\title{
HBxAg promotes HBV replication and EGFR activation in human placental trophoblasts
}

\author{
YAYUN LIN $^{1}$, YAN LIU ${ }^{2}$, DONGPING XU ${ }^{2}$, FANFAN GUO ${ }^{3}$, \\ WENTAO ZHANG $^{3}$, YIDAN ZHANG ${ }^{3}$ and GUIQIN BAI ${ }^{1}$ \\ ${ }^{1}$ Department of Gynecology and Obstetrics, The First Affiliated Hospital of Xi'an Jiaotong University, Xi'an, \\ Shaanxi 710061; ${ }^{2}$ Institute of Infectious Diseases, 5th Medical Center of Chinese PLA General Hospital, \\ Beijing 100141; ${ }^{3}$ College of Medicine, Xi'an Jiaotong University, Xi'an, Shaanxi 710061, P.R. China
}

Received June 26, 2020; Accepted June 9, 2021

DOI: $10.3892 / \mathrm{etm} .2021 .10645$

\begin{abstract}
Hepatitis B virus (HBV) infection is a global epidemic. The main transmission route of chronic HBV infection is from mother to child, yet the mechanisms underlying HBV intrauterine infection remain unclear. In the present study, the effect and the mechanism underlying hepatitis B virus $\mathrm{X}$ antigen (HBxAg) on $\mathrm{HBV}$ replication and EGFR activation in trophoblasts was investigated. Serum samples from pregnant women with $\mathrm{HBV}$ infection were used to infect trophoblasts and $\mathrm{HBxAg}$ expression was detected using ELISA. HBV plasmids carrying either full length hepatitis $B$ virus $\mathrm{X}(\mathrm{HBx})$ or $\mathrm{HBx}$ with a deletion mutation $(\triangle \mathrm{HBx})$ were transfected into trophoblasts and expression levels of HBV DNA, hepatitis B e-antigen and pregenomic (pg)RNA, and structural maintenance of chromosomes (Smc) 5/6 were assessed. The association between HBx and EGFR promoters was characterized using a luciferase reporter assay and EGFR/PI3K/phosphorylated (p)-AKT expression and apoptosis rate were also monitored. The results of the present study indicated that $\mathrm{HBx} \mathrm{Ag}$ expression increased with the increasing titre of HBV DNA $(\mathrm{P}<0.05)$. Compared with the wild-type group, the amount of HBV DNA in the supernatant and cells was significantly reduced $(\mathrm{P}<0.05)$ in the $\Delta \mathrm{HBx}$ group and the intracellular $\mathrm{HBeAg}$ and pgRNA levels were also significantly decreased $(\mathrm{P}<0.05)$. In addition, Smc5/6 expression was also significantly decreased $(\mathrm{P}<0.05)$ when the intracellular $\mathrm{HBx}$
\end{abstract}

Correspondence to: Professor Guiqin Bai, Department of Gynecology and Obstetrics, The First Affiliated Hospital of Xi'an Jiaotong University, 277 Yanta West Road, Xi'an, Shaanxi 710061, P.R. China

E-mail: baigq@126.com

Abbreviations: $\mathrm{HBx}$, hepatitis B virus X; HBV, hepatitis B virus; HBxAg, hepatitis B virus X antigen; Smc5/6, structural maintenance of chromosomes $5 / 6$

Key words: $\mathrm{HBx}$, trophoblasts, HBV DNA, Smc5/6, EGFR promoter protein was expressed compared with mock-transfected cells. Co-transfection of HBx and EGFR promoter plasmids in JEG-3 and HTR- 8 cells significantly elevated EGFR promoter driven luciferase expression relative to the control group $(\mathrm{P}<0.01)$. In EGFR overexpressing cells, the expression of $\mathrm{PI} 3 \mathrm{~K} / \mathrm{p}-\mathrm{AKT}$ was significantly increased, whereas the apoptosis rate was significantly decreased $(\mathrm{P}<0.05)$. These results were reversed in the EGFR-knockdown group. In conclusion, the present study demonstrated that $\mathrm{HBx}$ promotes $\mathrm{HBV}$ replication in trophoblasts via downregulation of Smc5/6, activates the EGFR promoter and inhibits trophoblast apoptosis via the PI3K/p-AKT downstream signalling pathway, thereby increasing the risk of $\mathrm{HBV}$ intrauterine infection.

\section{Introduction}

Hepatitis B virus (HBV) infection is a global epidemic. According to the World Health Organization, 2 billion people worldwide have been infected with $\mathrm{HBV}$, and chronic HBV infections account for 240 million of these cases (1). The incidence of HBV infection is high in China. The HBV carrying rate in the general Chinese population is $9.9 \%$, which closely correlates with the occurrence of chronic hepatitis, cirrhosis and liver cancer $(2,3)$. Mother-to-child transmission is the main transmission route of chronic HBV infection $(4,5)$. Mechanisms include intrauterine infection, intrapartum infection and puerperal infection (6). The latter two mechanisms can be prevented by treating the infant with the hepatitis $B$ vaccine and hepatitis B immunoglobulin immediately after birth (7). Despite these measures, 5-10\% of infants fail to acquire immunity (8-10). This is mainly attributed to intrauterine infection. However, the mechanisms underlying HBV intrauterine infection remain unclear.

Intrauterine infection via the placenta is a growing concern among clinical workers and scientific researchers. It is believed that mother-to-foetus HBV infection may be caused by introduction of HBV into circulating foetal blood from peripheral blood mononuclear cells through the placenta (11). HBV can integrate into placental trophoblastic cells, where it can replicate and produce intrauterine infection (12). Studies have demonstrated that hepatitis B surface antigen, hepatitis B core antigen and HBV DNA are distributed in all placental cell 
layers. The rate of HBV infection was demonstrated to gradually reduce in the placenta from the mother's side to the fetus' side $(13,14)$. Studies also indicate that in placental HBV infection, there is a gradual decreasing trend of trophoblast cells from the uterine interface to the villus vascular endothelial cells; however, the odds ratio (OR) value of foetal intrauterine infection gradually increases following the same pattern. This suggests that HBV can infect a foetus from the placenta via cell-to-cell transmission $(15,16)$.

Hepatitis B virus $\mathrm{X}(\mathrm{HBx})$ is a multi-functional regulatory protein with a wide range of trans-activating functions and can bind to a variety of intracellular factors involved in transcription and gene regulation $(17,18)$. Studies have demonstrated that HBx can promote viral transcription and replication in hepatoma cells $(19,20)$. HBx can stimulate different signalling pathways in cells, triggering a variety of biochemical and behavioural changes. It has been found in hepatoma cells that the primary function of $\mathrm{HBx}$ is to degrade structural maintenance of chromosomes 5/6, which restricts HBV replication by inhibiting HBV gene expression (21-23). In liver cells, HBx was revealed to activate viral and cell promoters and regulate signal transduction pathways (18). Previous research revealed that $\mathrm{HBV}$ can reach the placenta through maternal blood during pregnancy, where it infects placental trophoblast cells, producing HBx protein (24). HBx protein is associated with inhibition of trophoblast apoptosis by intracellular PI3K and the AKT signalling pathway $(24,25)$. HBx influences the activation of EGFR and other EGFR family members $(26,27)$.

The aim of the present study was to elucidate the mechanism underlying EGFR activation by hepatitis $B$ virus $X$ antigen (HBxAg) in placental trophoblast cells. The effect of EGFR activation on HBV replication was investigated by collecting serum samples from pregnant women with different HBV DNA titres. The samples were used to infect trophoblasts and $\mathrm{HBxAg}$ expression was detected. Wild-type plasmid containing the full length $\mathrm{HBV}$ genome and $\mathrm{HBx}$ deletion mutant $(\triangle \mathrm{HBx})$ plasmid were transfected into trophoblasts to mechanistically study the effects of $\mathrm{HBxAg}$ on HBV replication. Dual-luciferase activity assay and shRNA techniques were employed to study the effects of $\mathrm{HBx}$ protein on the EGFR promoter, EGFR/PI3K/phosphorylated (p)-AKT signalling and inhibition of trophoblast apoptosis, thereby establishing the role of $\mathrm{HBx} \mathrm{Ag}$ in $\mathrm{HBV}$ intrauterine infection.

\section{Materials and methods}

Blood sample collection. HBV serum was collected from four pregnant women diagnosed with chronic hepatitis B, who had been admitted to the First Affiliated Hospital of Xi'an Jiaotong University (Shaanxi, China), between February 2018 and March 2018. Informed written consent was obtained from all study participants following a detailed explanation of the study at the time of blood and serum collection. The study protocol was approved by the Institutional Review Board of the First Affiliated Hospital, Xi'an Jiaotong University.

Serum HBV DNA titres were obtained from each donor respectively: i) $4.05 \times 10^{2} \mathrm{IU} / \mathrm{ml}$; ii) $7.65 \times 10^{3} \mathrm{IU} / \mathrm{ml}$; iii) $3.28 \times 10^{5} \mathrm{IU} / \mathrm{ml}$; and iv) $8.99 \times 10^{7} \mathrm{IU} / \mathrm{ml}$. The donors were $28 \pm 4$ weeks pregnant and aged between $27.5 \pm 2.5$ years old. Control serum was collected in the same date range as the
HBV serum samples from healthy pregnant women admitted to the First Affiliated Hospital of Xi'an Jiaotong University. The control donors were $28 \pm 4$ weeks and aged between $27.5 \pm 2.5$ years. These patients had no history of hepatitis B or other diseases.

Construction and validation of a full-length $H B V$ vector expression plasmid with $H B x$ gene deletion. To create an $\mathrm{HBx}$ deletion mutation in the pTriEx-1.1 HBV vector (gifted from Professor Xu Dongping, 5th Medical Center of the Chinese PLA General Hospital) encoding the entire HBV sequence, the CAA codon encoding the eighth glutamine in the HBx coding sequence was mutated to the termination codon TAA. The forward and reverse primers (Beijing Tianyi Huiyuan Biotechnology Co., Ltd.) encoding the mutation were designed as follows: ptxup, 5'-TAACTGGATCCTGCGCGGGACGTC CT-3'; ptxlow, 5'-GCGCAGGATCCAGTTAGCAGCACA TC-3'. Site-directed mutagenesis was accomplished using a Fast Mutagenesis System kit (TransGen Biotech Co., Ltd.) according to manufacturer's instructions. Reaction conditions were as follows: Initial denaturation at $94^{\circ} \mathrm{C}$ for $5 \mathrm{~min} ; 25$ cycles of $94^{\circ} \mathrm{C}$ for $20 \mathrm{sec}, 60^{\circ} \mathrm{C}$ for $20 \mathrm{sec}$ and $72^{\circ} \mathrm{C}$ for $3 \mathrm{~min}$; and a final extension at $72^{\circ} \mathrm{C}$ for $10 \mathrm{~min}$. Next, $1 \mu \mathrm{l}$ DMT enzyme (modified DpnI restriction endonuclease; Beijing TransGen Biotech Co., Ltd.) was added to the PCR products and digested at $37^{\circ} \mathrm{C}$ for $1 \mathrm{~h}$. The product was directly translated into the DMT chemically competent cells (cat. no. CD511-01; TransGen Biotech Co., Ltd.), coated on the Luria-Bertani (LB) tablet containing ampicillin $(50 \mu \mathrm{g} / \mathrm{ml}$; Gibco; Thermo Fisher Scientific, Inc.) and incubated at $37^{\circ} \mathrm{C}$ overnight. Five white colonies were randomly selected for culture and the bacterial solution was used for PCR. Specific steps were as follows: A total of $11 \mu \mathrm{l}$ sterile water were added to the PCR tube, a single white colony was picked and lightly rinsed several times in the PCR tube, the toothpick was removed and lightly streaked on an LB tablet, and a replication plate was prepared. The PCR tube was placed on ice immediately after incubation for $10 \mathrm{~min}$ at $94^{\circ} \mathrm{C}$. After the bacterial cell was lysed, DNA was released as a template for amplification and electrophoresis identification. The reaction conditions were as follows: Initial denaturation at $94^{\circ} \mathrm{C}$ for $3 \mathrm{~min} ; 20$ cycles of $94^{\circ} \mathrm{C}$ for $40 \mathrm{sec}, 60^{\circ} \mathrm{C}$ for $100 \mathrm{sec}$ and $72^{\circ} \mathrm{C}$ for $4 \mathrm{~min}$; and a final extension at $72^{\circ} \mathrm{C}$ for $10 \mathrm{~min}$. Mutated plasmid samples were sent for sequencing (Beijing Tianyi Huiyuan Biotechnology Co., Ltd.).

Cell culture and transfection. Human choriocarcinoma cell line JEG-3 (ATCC ${ }^{\circledR}$ HTB-36 ${ }^{\mathrm{TM}}$; Shanghai Life Sciences Research Institute) was cultured in DMEM (Gibco; Thermo Fisher Scientific, Inc.) supplemented with 10\% FBS (Gibco; Thermo Fisher Scientific, Inc.), $100 \mathrm{U} / \mathrm{ml}$ penicillin and $0.1 \mathrm{mg} / \mathrm{ml}$ streptomycin (Gibco; Thermo Fisher Scientific, Inc.). Human trophoblast cell line, HTR-8/SVneo (ATCC CRL-3271 ${ }^{\mathrm{TM}}$; Laboratory of Obstetrics and Gynecology, Tangdu Hospital) was cultured in RPMI-1640 (Gibco; Thermo Fisher Scientific, Inc.) supplemented with 10\% FBS (Gibco; Thermo Fisher Scientific, Inc.), $100 \mathrm{U} / \mathrm{ml}$ penicillin and streptomycin (Gibco; Thermo Fisher Scientific, Inc.). The HTR-8/SVneo cell line was developed by Graham et al (28). It was generated using freshly isolated extravillous cytotrophoblasts from first trimester placenta and transfected with 
a plasmid containing the simian virus 40 large $\mathrm{T}$ antigen (SV40). The results of a previous study demonstrated that this cell line contains two populations, one of epithelial and one of mesenchymal origin (29). All cell lines were incubated at $37^{\circ} \mathrm{C}$ in $5 \% \mathrm{CO}_{2}$. Cells were inoculated in 12-well plates until the cell density reached $50-60 \%$ confluence. Cell culture medium was discarded, and cells were incubated with $30 \%$ HBV DNA serum (HBV DNA titres: $1 \times 10^{2}, 1 \times 10^{3}, 1 \times 10^{5}$ and $1 \times 10^{7}$ ) and $30 \%$ control human serum at $37^{\circ} \mathrm{C}$ for $72 \mathrm{~h}$. In subsequent experiments, $2 \mu \mathrm{g}$ of plasmids (full length wild-type $1.1 \mathrm{HBV}$ plasmid, HBx deletion mutant plasmid; pGFP-HBx plasmid, pGFP empty vector) were mixed with $4 \mu \mathrm{l}$ X-tremeGENE HP (Roche Diagnostics) at room temperature for $20 \mathrm{~min}$ when cell densities reached $50-60 \%$ confluence. The mixtures were added to culture media and incubated for $72 \mathrm{~h}$. The experiments were repeated at least three times independently. The optimal time point was determined by detecting $24,48,72$ and $96 \mathrm{~h}$ (data not shown).

HBV DNA quantitation in cells and supernatants. Following $72 \mathrm{~h}$ transfection, cells were collected, cleaved on $0.5 \%$ NP-40 at $4^{\circ} \mathrm{C}$ for $30 \mathrm{~min}$ and supernatant was extracted by centrifugation $\left(13,000 \times \mathrm{g}, 7 \mathrm{~min}, 4^{\circ} \mathrm{C}\right.$ ). DNase I (New England Biolabs, Inc.) was added to digest DNA at $37^{\circ} \mathrm{C}$ for $5 \mathrm{~h}$ and proteinase $\mathrm{K}$ (Merck KGaA) was then added to digest in a $42^{\circ} \mathrm{C}$ water bath overnight. Equal volumes of phenol/chloroform/isoamyl alcohol mixture were added (total volume, $660 \mu \mathrm{l}$ ). Following centrifugation $\left(10,000 \mathrm{x} \mathrm{g}, 15 \mathrm{~min}, 25^{\circ} \mathrm{C}\right)$, the supernatant was transferred to a new tube, $1 / 10$ volume $3 \mathrm{M} \mathrm{NaAc}$ and isopropyl alcohol were added and mixed at room temperature for $5 \mathrm{~min}$. The mixture was then centrifuged at 13,000 $\mathrm{x}$ g for $30 \mathrm{~min}$ at $4^{\circ} \mathrm{C}$ and washed once with $500 \mu 175 \%$ ethanol. The mixture was centrifuged again at $13,000 \times \mathrm{g}$ for $15 \mathrm{~min}$ at $4^{\circ} \mathrm{C}$ and dried. Finally, HBV DNA was dissolved with $30 \mu \mathrm{l}$ double-distilled $\mathrm{H}_{2} \mathrm{O}$. The supernatant and viral DNA samples were sent for HBV DNA quantification (Beijing NaGene Diagnosis Reagent Co., Ltd.).

Western blotting. Cells were lysed with $150 \mu \mathrm{l}$ RIPA (CoWin Biosciences) buffer and 1.5 $\mu \mathrm{l}$ PMSF (CoWin Biosciences) was added. The protein concentration was determined using a BCA protein assay kit and $20 \mu \mathrm{g}$ of protein from each sample was separated using $12 \%$ SDS-PAGE before transferring to PVDF membranes for immunoblotting. The membranes were rinsed for 3 min with $1 \mathrm{X}$ TBST $(0.05 \%$ Tween-20; Thermo Fisher Scientific, Inc.) on a shaker. The membranes were subsequently blocked with 5\% skimmed milk (Thermo Fisher Scientific, Inc.) on a shaker at $25^{\circ} \mathrm{C}$ for $2 \mathrm{~h}$. The following primary antibodies and dilutions were used (incubated at $4^{\circ} \mathrm{C}$ for $16 \mathrm{~h}$ ): Rabbit anti-HBx antibody (1:300; cat. no. ab2741; Abcam), rabbit anti-structural maintenance of chromosomes (Smc)5 antibody (1:500; cat. no. ab154103; Abcam), rabbit anti-Smc6 antibody (1:500; cat. no. ab155495; Abcam), rabbit anti-EGFR antibody (1:1,000; cat. no. ab52894; Abcam), rabbit anti-PI3K antibody (1:500; cat. no. 4249; Cell Signaling Technology, Inc.), rabbit anti-AKT antibody (1:800; cat. no. 4691T; Cell Signaling Technology, Inc.), rabbit anti-p-AKT antibody (1:500; cat. no. 4060; Cell Signaling Technology, Inc.) and mouse anti-human $\beta$-actin antibody (1:1,000; cat. no. CW0096; CoWin Biosciences). After incubation with HRP-labelled goat anti-mouse/rabbit IgG secondary antibody at $25^{\circ} \mathrm{C}$ for $1 \mathrm{~h}$ (1:2,000; cat. no. CW0102/0103; CoWin Biosciences), proteins were detected using a ChemiDoc ${ }^{\mathrm{TM}}$ XRS imaging system (Bio-Rad Laboratories, Inc.). The experiments were repeated at least three times independently.

ELISA. The cells infected with HBV serum in vitro were collected, and HBxAg was detected using Diagnostic kit for hepatitis B virus X antigen (ELISA) (cat. no. DM00914; Shanghai Duma Biological Technology Co., Ltd.). The cells transfected with full length wild-type $1.1 \mathrm{HBV}$ plasmid and $\mathrm{HBx}$ deletion mutant plasmid were collected, and $\mathrm{HBeAg}$ was detected using Diagnostic kit for hepatitis B virus e antigen (ELISA) (cat. no. HBeAg-96T; Beijing Wantai Biopharmaceutical Co., Ltd.). A total of $100 \mu \mathrm{l} /$ well samples and enzyme conjugate were added in 96-well ELISA plates for $1 \mathrm{~h}$ incubation at $37^{\circ} \mathrm{C}$. The board was washed with washing solution from the kit for 5 times and patted dry. Developer A and $\mathrm{B}$ liquid was added to each hole and incubated at $37^{\circ} \mathrm{C}$, avoiding light for $15 \mathrm{~min}$ to aid color development. The termination liquid was added and shaken gently to mix. The absorbance was read at $450 \mathrm{~nm}$ within $30 \mathrm{~min}$.

pgRNA quantification. Total RNA was extracted from cells using an EasyPure Viral DNA/RNA kit (TransGen Biotech Co., Ltd.) and RNase inhibitors were regularly sprayed throughout the experiment (DNase I and RNase-free; Thermo Fisher Scientific, Inc.). DNA was digested, DNase was inactivated, reverse transcriptase primers were added and cDNA was synthesised using reverse transcriptase kits (Transcriptor First Strand cDNA Synthesis Kit; Roche Diagnostics). cDNA, primers, probes and MIX [2xRealStar Power Probe Mixture UNG; Beijing Kangrun Chengye Biotechnology Co., Ltd. (GenStar)] were proportionally mixed to determine pgRNA concentrations using RT-qPCR. The results were quantified as described previously $(30,31)$. The linear regression equation was obtained by taking the logarithm value of the concentration of the standard and that of the $\mathrm{Ct}$ value. The logarithm value of the concentration according to the $\mathrm{Ct}$ value of the sample was calculated, and finally the concentration of pgRNA was calculated. Primers and probes (Beijing Tianyi Huiyuan Biotechnology Co., Ltd.) were as follows: HR-F2: 5'-AGACCACCAAATGCCCCT-3'; HR-R2: 5'-TCACACCGT AACACACGACAC-3'; HR-RT2: 5'-TCTCACACCGTAACA CACGACACAGGCGAGGGAGTTCTTCTTCTA-3'; Probe HR: 5'-CAACACTTCCGGARACTACTGTTGTTAGACG-3'. Reaction conditions were as follows: $50^{\circ} \mathrm{C}$ for $5 \mathrm{~min} ; 94^{\circ} \mathrm{C}$ for $10 \mathrm{~min} ; 45$ cycles of $94^{\circ} \mathrm{C}$ for $15 \mathrm{sec}$ and $58^{\circ} \mathrm{C}$ for $40 \mathrm{sec}$.

Immunofluorescence assays. Cells were seeded onto $\mu$-Slide 8 -well chamber slides $\left(4.5 \times 10^{4}\right.$ cells/well; Ibidi GmbH) and transfected with plasmids (full length wild-type 1.1 HBV plasmid, HBx deletion mutant plasmid; pGFP-HBx plasmid, pGFP empty vector). After incubation at $37^{\circ} \mathrm{C}$ for $48 \mathrm{~h}$, the cells were fixed in $4 \%$ paraformaldehyde at $25^{\circ} \mathrm{C}$ for 20 min, permeabilized in $0.1 \%$ Triton X-100 for 10 min and blocked with 3\% BSA (Gibco; Thermo Fisher Scientific, Inc.) for $2 \mathrm{~h}$ at room temperature. Cells were incubated with primary antibodies before staining with Cy3-conjugated goat anti-rabbit IgG (1:500; cat. no. CW0159; CoWin Biosciences) in the dark for $40 \mathrm{~min}$ at $37^{\circ} \mathrm{C}$. The following 
primary antibodies and dilutions were used (incubated at $37^{\circ} \mathrm{C}$ for 2 h): Anti-HBx (1:150; cat. no. ab2741; Abcam), anti-Smc5 (1:200; cat. no. ab154103; Abcam), anti-Smc6 (1:200; cat. no. ab155495; Abcam), anti-EGFR (1:500; cat. no. ab52894; Abcam), anti-PI3K (1:200; cat. no. 4249; Cell Signaling Technology, Inc.), anti-AKT (1:400; cat. no. 4691T; Cell Signaling Technology, Inc.) and anti-p-AKT (1:200; cat. no. 4060; Cell Signaling Technology, Inc.). Cell nuclei were stained with DAPI at $25^{\circ} \mathrm{C}$ for $10 \mathrm{~min}$. The cells were washed three times with 1 x PBS between each step. Images were captured using an Olympus FV1000 confocal microscope (Olympus Corporation). All confocal images were captured using the same imaging parameters and $\geq 10$ images for each sample were examined. Fluorescence intensity was analyzed by Image-Pro Plus 6.0 software (Media Cybernetics, Inc.).

Dual-luciferase reporter assay. Cells were seeded into 24-well plates at $3 \times 10^{5}$ cells/well and incubated for 16-18 h. pGL3-EGFR promoter luciferase expression vector (BK328 pGL3-basic-EGFR; Umibio (Shanghai) Co. Ltd.) and the internal reference vector pRL-TK (Promega Corporation) were co-transfected with X-tremeGENE HP (Roche Diagnostics) at room temperature for $20 \mathrm{~min}$ when cell densities reached $50-60 \%$ confluence, at a ratio of 30:1 (expression vector $0.3 \mu \mathrm{g} /$ well and internal reference $0.01 \mu \mathrm{g} /$ well). pGL3-EGFR promoter luciferase expression vector and pGFP-HBx (Addgene, Inc.) were co-transfected as the experimental group, pGL3-EGFR promoter luciferase expression vector and pGFP empty vector (Addgene, Inc.) were co-transfected as the control group, pGL3-Basic and pGFP-HBx were co-transfected as a negative control (NC) and pGL3-Control was used as a positive control (Promega Corporation). Cells were lysed $48 \mathrm{~h}$ later and assayed for luciferase activity. Firefly luciferase activity was normalized to internal reference Renilla luciferase activity. A single-tube multifunctional detection reagent was used to detect luciferase activity according to kit instructions (Dual-Luciferase Reporter Assay; Promega Corporation).

Construction of cell lines stably expressing EGFR. Cells were seeded into 24 -well plates at $9.5 \times 10^{4}$ cells/well and incubated at $37^{\circ} \mathrm{C}$ for $16-18 \mathrm{~h}$. Spent culture medium was removed before adding fresh complete culture medium. A titred solution of EGFR overexpressing lentivirus particles [GeneCopoeia, Inc.; lentivirus volume (unit: $\mathrm{ml}$ )=the number of cells exposed to lentivirus x MOI/lentivirus titre (unit: TU/ml)] was added to the cells and gently mixed. Culture medium containing lentivirus particles was harvested after 12-16 h of infection at $37^{\circ} \mathrm{C}$ and fresh complete culture medium was added to the culture plate to continue culturing the cells. The negative control (NC) group was infected with irrelevant control lentiviral vector. GFP fluorescence was observed at 72-96 h post infection. After $72 \mathrm{~h}$ of infection, $2 \mu \mathrm{g} / \mathrm{ml}$ of puromycin was added to select for infected cells. In subsequent experiments, when cell densities reached 50-60\% confluence, $2 \mu \mathrm{g}$ of EGFR short hairpin (sh)RNA (Vigene Bioscience Inc.) and shRNA control vector (Vigene Bioscience Inc.) were mixed with $4 \mu \mathrm{l}$ X-tremeGENE HP (Roche Diagnostics) at room temperature for $20 \mathrm{~min}$, respectively. The mixtures were added to culture media and incubated at $37^{\circ} \mathrm{C}$ for $72 \mathrm{~h}$. As shown in Fig. S1, EGFR expression in the overexpressing cells was knocked down using EGFR short hairpin (sh)RNA.
Detection of cell apoptosis using flow cytometry. Cell apoptosis was detected using a cell apoptosis kit from Nanjing KeyGen Biotech Co., Ltd. Following transfection at $37^{\circ} \mathrm{C}$ for $48 \mathrm{~h}$ (EGFR overexpressing cells), the medium was removed and cells $\left(2.0 \times 10^{5}\right.$ cells/well) were washed twice with pre-cooled PBS. The supernatant was removed, and cells were suspended in $300 \mu \mathrm{l}$ of $1 \mathrm{X}$ binding buffer (at a density of $5 \times 10^{5}-5 \times 10^{6}$ cells $/ \mathrm{ml}$ ). A total of $5 \mu \mathrm{l}$ Annexin V FITC and $5 \mu \mathrm{l}$ PI were added into the suspension and the mixture was incubated at $25^{\circ} \mathrm{C}$ for $10 \mathrm{~min}$ in the dark. Each sample was analyzed using flow cytometry (Gallios; Beckman Coulter, Inc.) within $1 \mathrm{~h}$. The results of apoptosis were analysed by FlowJo v10 software (Becton, Dickinson and Company). The experiments were repeated at least three times independently. The proportion of apoptosis was calculated from the sum of Q3 and Q2.

Statistical analysis. Band intensities in scanned western blots were quantitated using ImageJ v1.8.0.112 software (National Institutes of Health). Fluorescence intensities were analysed using Image-Pro Plus software (Media cybernetics Inc.). Data were expressed as the mean \pm standard deviation. Differences among variables were examined using unpaired Student's t-test or one-way ANOVA with Bonferroni's multiple comparison correction. Statistical analyses were performed using SPSS version 18.0 (SPSS, Inc.). $\mathrm{P}<0.05$ was considered to indicate a statistically significant difference.

\section{Results}

HBxAg expression in placental trophoblast cells infected with $H B V$ serum in vitro. The serum of patients with HBV demonstrated an ability to infect JEG-3 and HTR-8 cells in vitro (Fig. 1A). When the concentration of HBV-containing serum was $30 \%$ in the culture medium, HBxAg expression gradually increased with increasing amounts of HBV DNA in patient serum. No HBxAg was detected in the no serum control group or the HBV DNA negative serum group.

HBxAg expression in each group was compared in JEG-3 cells. With the exception of the HBV DNA negative serum group, $\mathrm{HBx} A g$ expression was significantly higher than in the no serum control group. There was no difference in $\mathrm{HBxAg}$ expression between group $1 \times 10^{2}$ and group $1 \times 10^{3}$. $\mathrm{HBx} \mathrm{Ag}$ expression of group $1 \times 10^{5}$ was significantly higher than that of group $1 \times 10^{3}(31.05 \%)$. Furthermore, HBxAg expression of group $1 \times 10^{7}$ increased by $11.26 \%$ compared with that of group $1 \times 10^{5}$.

HBxAg expression in each group of HTR-8 cells was compared. With the exception of the HBV DNA negative serum group, $\mathrm{HBx} A g$ expression in all other groups was significantly higher than in the no serum control group. There was no difference in HBxAg expression between group $1 \times 10^{2}$ and group $1 \times 10^{3}$. HBxAg expression of group $1 \times 10^{5}$ significantly increased (39.68\%) compared with that of group $1 \times 10^{3}$. Further, $\mathrm{HBxAg}$ expression of group $1 \times 10^{7}$ increased by $14.21 \%$ compared with that of group $1 \times 10^{5}$, but the difference was not significant.

Western blot analysis of HBx and Smc5/6 protein expression. As demonstrated in Fig. 1B, HBx expression was observed in JEG-3 and HTR-8 cells transfected with HBx plasmid. Smc5/6 expression was significantly higher in green fluorescent protein 

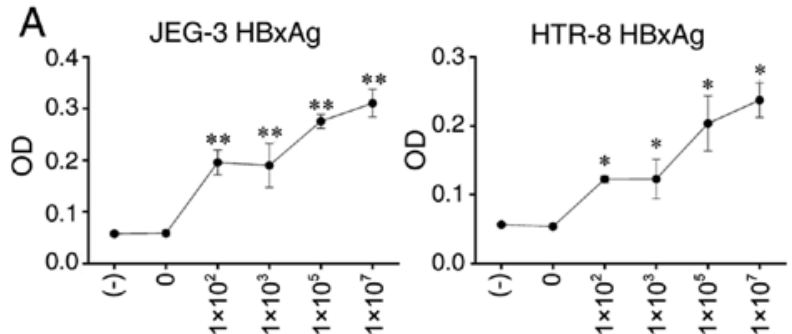

Serum HBV DNA titres (IU/ml) Serum HBV DNA titres (IU/ml)
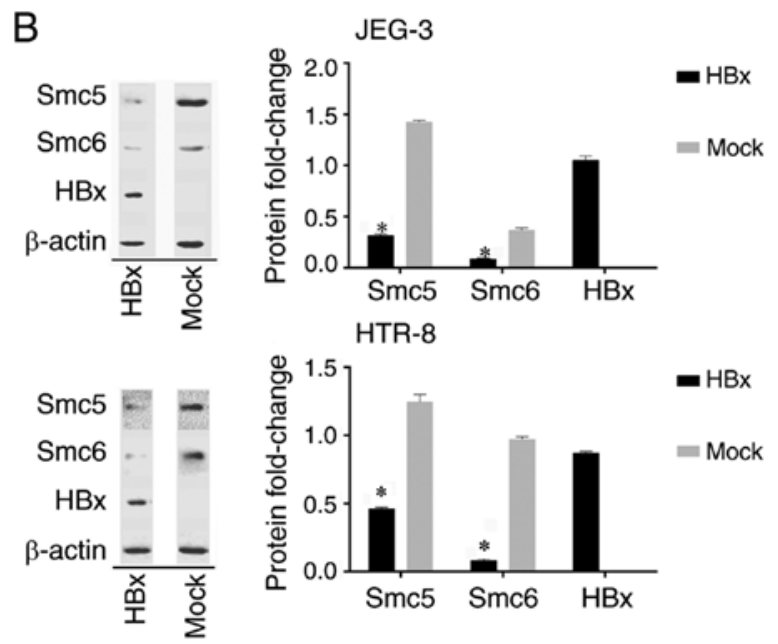

Figure 1. (A) HBxAg expression in trophoblasts infected with HBV serum in vitro. (-), no serum control group; 0, HBV DNA negative serum group; $1 \times 10^{2}, 1 \times 10^{3}, 1 \times 10^{5}$ and $1 \times 10^{7}$ are the serum HBV DNA titres. ${ }^{*} \mathrm{P}<0.05$, ${ }^{* *} \mathrm{P}<0.01$ vs. (-). (B) Western blot analysis of $\mathrm{HBx}$ and $\mathrm{Smc} 5 / 6$ protein expression. Protein fold-change is displayed as the ratio of $\mathrm{HBx}$ and Smc5/6 to $\beta$-actin. The blots/different groups were run on the same membrane. Mock, pGFP empty vector; HBx, pGFP-HBx plasmid. "P<0.05 vs. Mock. HBxAg, hepatitis B virus $\mathrm{X}$ antigen; $\mathrm{HBV}$, hepatitis B virus; Smc5/6, structural maintenance of chromosomes $5 / 6$; $\mathrm{HBx}$, hepatitis B virus $\mathrm{X}$.

(GFP) empty vector (pGFP)-transfected cells than in cells in which HBx protein was expressed.

Comparison of HBV DNA replication levels in placental trophoblast cells. HBV DNA replication in JEG-3 cell supernatant and JEG-3 cells in the $\triangle \mathrm{HBx}$ group was significantly reduced by 98.1 and $96.1 \%$ respectively, compared with that in the wild-type HBV group (Fig. 2A). HBV DNA replication in HTR- 8 cell supernatant and HTR- 8 cells in the $\triangle$ HBx group was significantly decreased by 98.8 and $99.0 \%$ respectively, compared with that in the wild-type HBV group.

Comparison of HBeAg expression in placental trophoblast cells. The OD values for HBeAg in the $\triangle \mathrm{HBx}$ group were significantly lower in JEG-3 and HTR-8 cells than in the 1.1 HBV group (Fig. 2B).

Comparison of pgRNA in placental trophoblast cells. The pgRNA levels in JEG-3 cells transfected with $\triangle \mathrm{HBx}$ plasmid were $99.0 \%$ lower than in wild-type HBV-transfected cells. pgRNA levels in $\triangle \mathrm{HBx}$-transfected HTR-8 cells were $99.4 \%$ lower than in wild-type HBV-transfected cells (Fig. 2C).

Confocal laser microscopy analysis of HBx and Smc5 protein expression and localization. As revealed in Fig. 3A, HBx
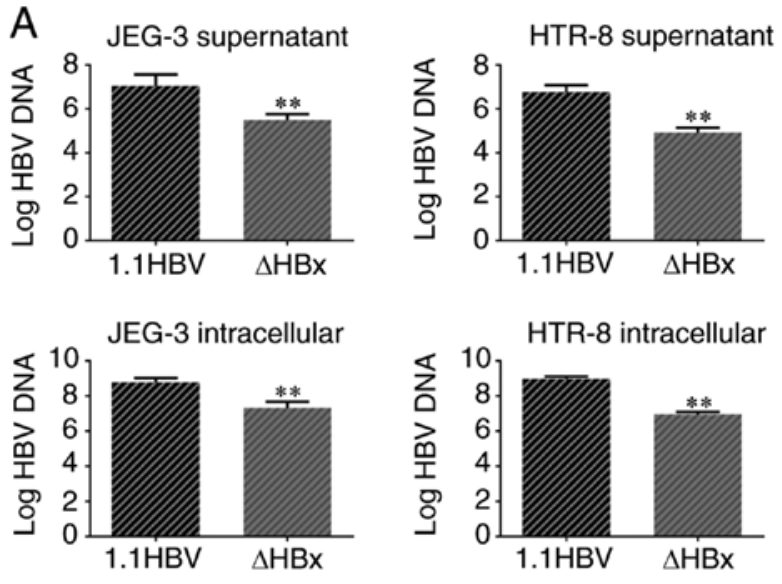

B
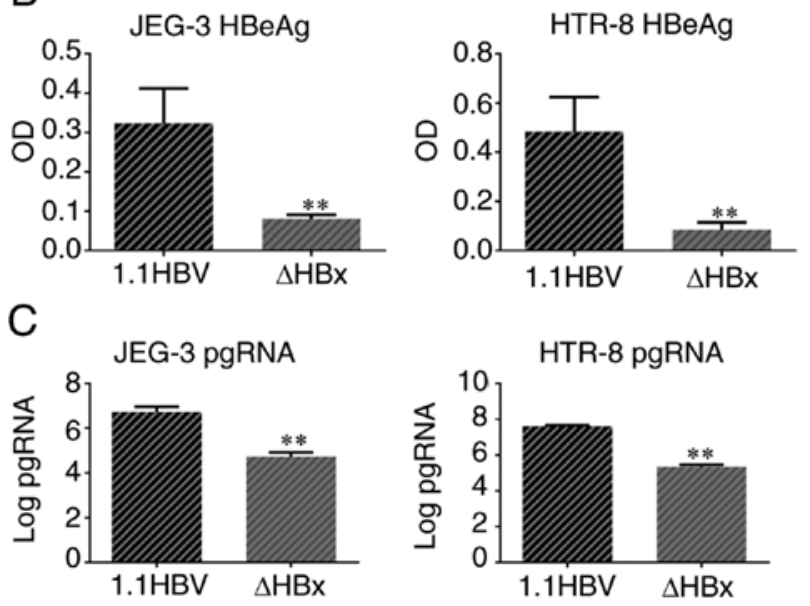

Figure 2. (A) Comparison of HBV DNA replication levels in trophoblasts. (B) Comparison of $\mathrm{HBeAg}$ expression in trophoblasts. (C) Comparison of pgRNA levels in trophoblasts. ${ }^{* *} \mathrm{P}<0.01$ vs. $1.1 \mathrm{HBV}$. HBV, hepatitis B virus; $\mathrm{HBx}$, hepatitis B virus X; HBeAg, hepatitis B e-antigen; pg, pregenomic; 1.1 $\mathrm{HBV}$, full length wild-type $1.1 \mathrm{HBV}$ plasmid; $\triangle \mathrm{HBx}, \mathrm{HBx}$ deletion mutant plasmid.

protein expression was detected when JEG-3 and HTR-8 cells were transfected with $\mathrm{HBx}$ and $1.1 \mathrm{HBV}$ plasmids. $\mathrm{HBx}$ protein expression was not detected in cells transfected with $\triangle \mathrm{HBx}$ or pGFP. HBx protein localized to the cytoplasm in both cell types. Smc5 protein was mainly expressed in the nucleus and Smc5 expression was higher in $\triangle H B x$-transfected or pGFP-transfected cells than in cells in which HBx protein was expressed. Protein levels were consistent with western blotting results.

Dual-luciferase reporter gene assay of $H B x$ activity on the EGFR promoter. As demonstrated in Fig. 4A, co-transfection of HBx and EGFR promoter plasmids in JEG-3 and HTR-8 cells significantly elevated EGFR promoter driven luciferase expression relative to the control group, which was co-transfected with EGFR promoter and pGFP empty vector.

Western blot analysis of EGFR/PI3K/p-AKT expression. EGFR protein expression was higher in the EGFR overexpressing cells than that in the shEGFR-transfected cells or the NC group (JEG-3; Fig. 4B). When the EGFR overexpressing cells were transfected with shEGFR, intracellular EGFR 
A

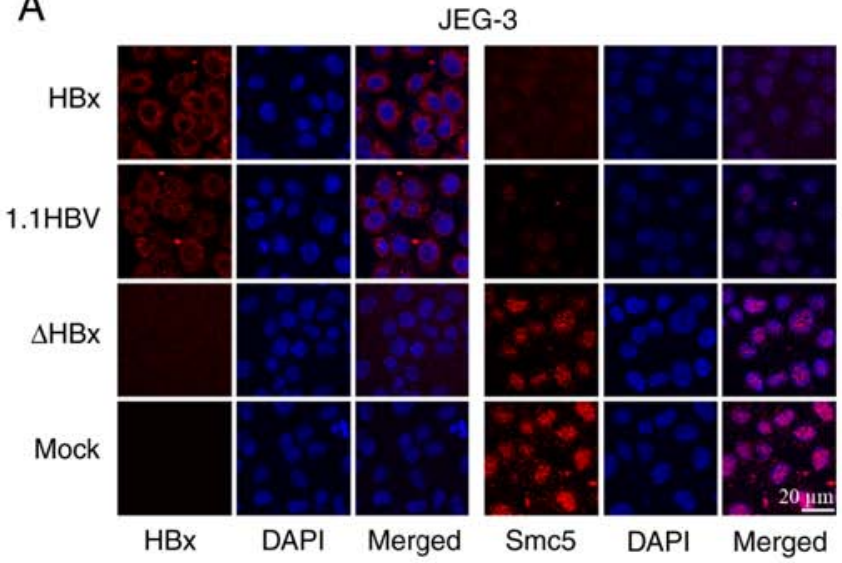

HTR-8

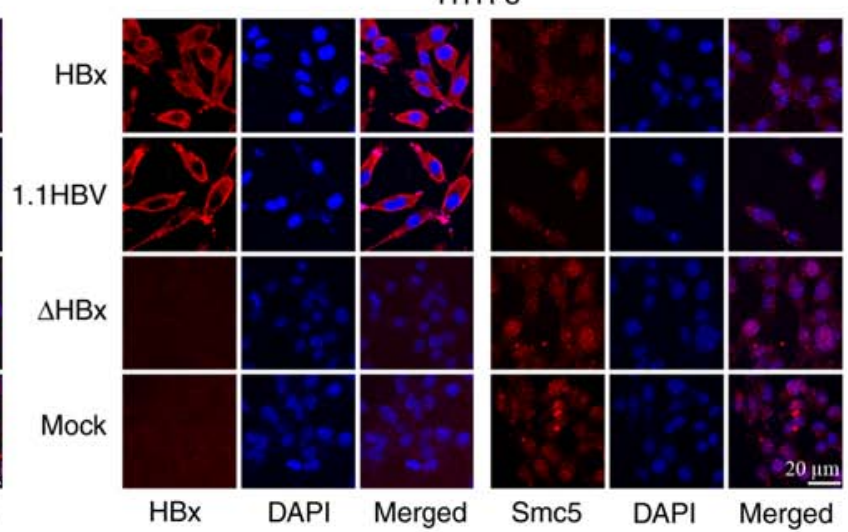

B
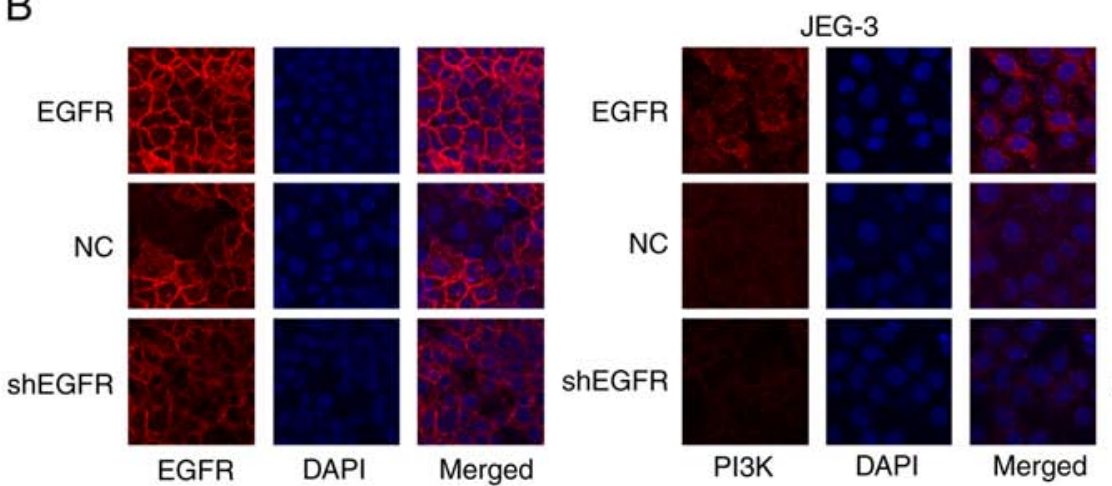

HTR-8
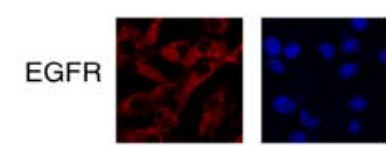

NC

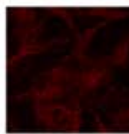

shEGFR

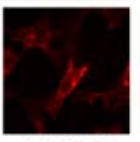

EGFR
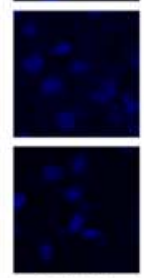

DAPI
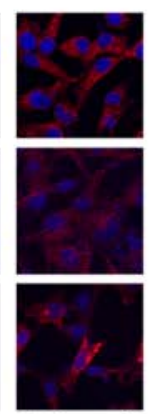

Merged
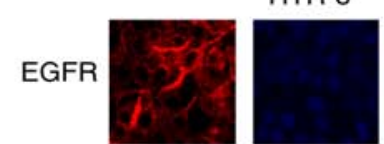

NC

ShEGFR

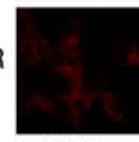

PI3K
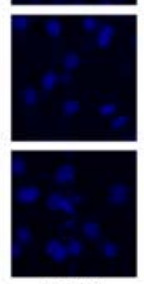

DAPI

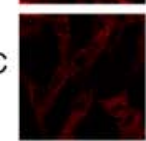

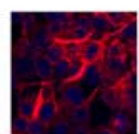
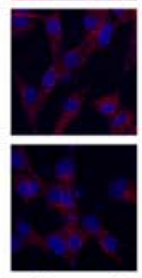

Merged

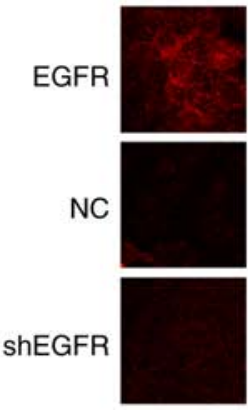

p-Akt

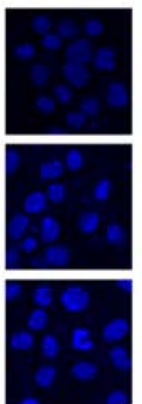

DAPI

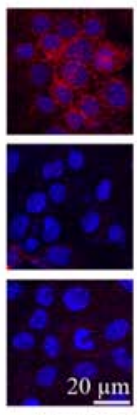

Merged
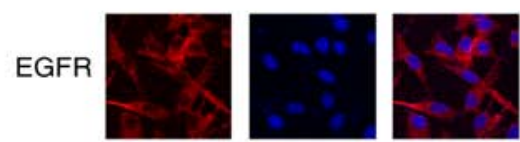

NC
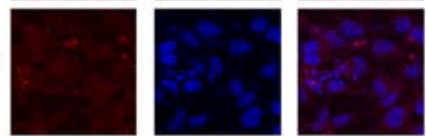

ShEGFR

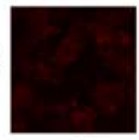

p-Akt

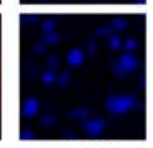

DAPI

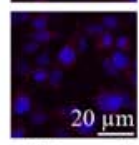

Merged

Figure 3. (A) Confocal laser microscopy analysis of HBx and Smc5 protein expression and localization. The nuclei stained with DAPI showed blue fluorescence, the HBx and Smc5 proteins showed red fluorescence and the merged showed two overlapping fluorescence images. (B) Confocal laser microscopy analysis of EGFR/PI3K/p-AKT protein expression and localization. The nuclei stained with DAPI showed blue fluorescence, the EGFR/PI3K/p-AKT proteins showed red fluorescence and the merged showed two overlapping fluorescence images. Magnification, $\mathrm{x} 400$. Scale bar, $20 \mu \mathrm{m}$. Smc5, structural maintenance of chromosomes 5; HBx, hepatitis B virus X; EGFR, EGFR overexpressing cells; NC, negative control; sh, short hairpin; HBx, pGFP-HBx plasmid; 1.1 HBV, full length wild type $1.1 \mathrm{HBV}$ plasmid; $\triangle \mathrm{HBx}, \mathrm{HBx}$ deletion mutant plasmid; mock, pGFP empty vector.

expression was significantly decreased in both cell types as compared with that in EGFR overexpressing cells. When EGFR was overexpressed, PI3K and p-AKT levels were significantly higher in both cell types than in shEGFR-transfected cells and NC group. There was no difference in AKT expression between groups.

Confocal laser microscopy analysis of EGFR/PI3K/p-AKT protein expression and localization. EGFR, PI3K and p-AKT were found in the cytoplasm. As highlighted in Fig. 3B, EGFR protein expression in the stable EGFR-overexpressing cells was higher than in the shEGFR-expressing group and NC group. When stable EGFR-overexpressing cells were transfected with shEGFR, intracellular EGFR expression in both cell types was lower than in the parent EGFR overexpressing cells. EGFR overexpression in both cell types increased PI3K and p-AKT levels as compared with those in shEGFR-transfected cells and NC group. Protein levels were consistent with western blotting results.

Association between EGFR expression and apoptosis. As indicated in Fig. 5, the apoptosis percentage in HTR-8 and JEG-3 cells was significantly lower than in NC group when EGFR was overexpressed. When each type of stable EGFR-overexpressing cell was transfected with shEGFR, the percentage of apoptotic cells increased significantly. The percentage of apoptotic cells was negatively associated with EGFR/PI3K/p-AKT expression. 

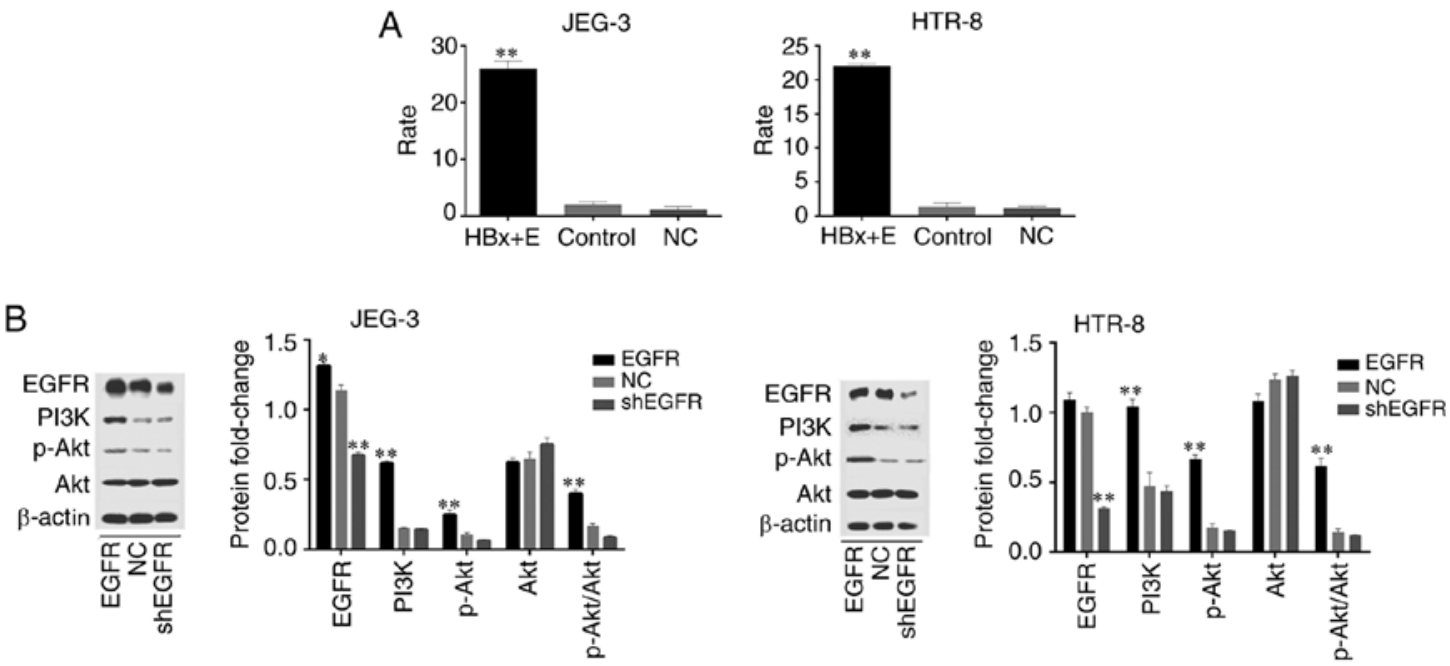

Figure 4. (A) Dual-luciferase reporter gene assay of HBx activity on the EGFR promoter. HBx + E, co-transfection of pGFP-HBx and pGL3-EGFR promoter plasmids; control, co-transfection of pGFP empty vector and pGL3-EGFR promoter plasmids; NC, co-transfection of pGFP-HBx and pGL3-basic empty vector. Rate, firefly luciferase and internal reference Renilla luciferase ratio. ${ }^{* * *} \mathrm{P}<0.01$ vs. control. (B) Western blot analysis of EGFR/PI3K/p-AKT expression. Protein fold change is displayed as the ratio of the EGFR/PI3K/p-Akt/Akt protein band to the $\beta$-actin protein band; p-AKT/AKT, the ratio of p-AKT protein band to the AKT protein band. "P<0.05, ${ }^{* *} \mathrm{P}<0.01$ vs. NC. EGFR, EGFR overexpressing cells; NC, negative control; sh, short hairpin; HBx, hepatitis B virus $\mathrm{X} ; \mathrm{p}-$, phosphorylated.

JEG-3
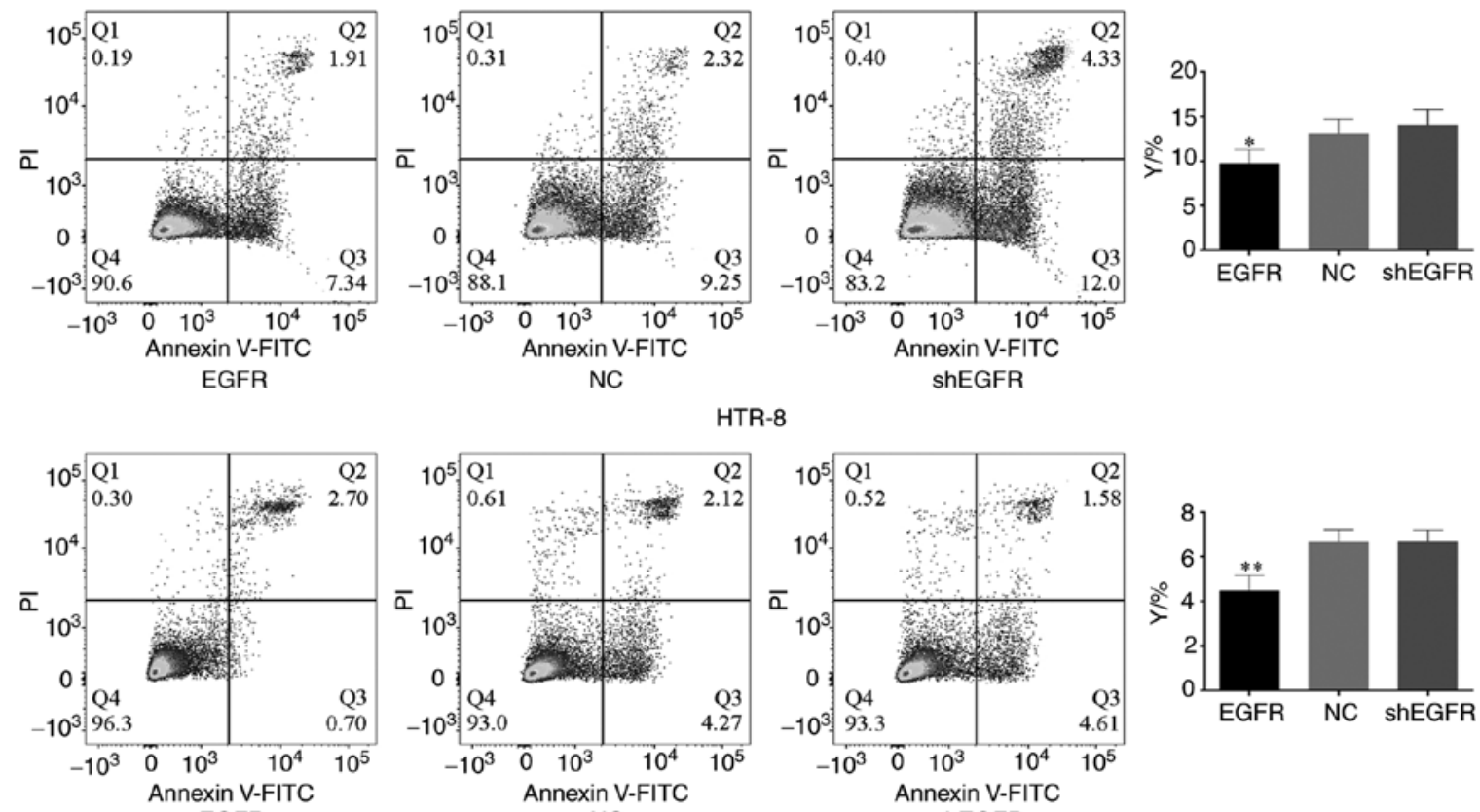

EGFR

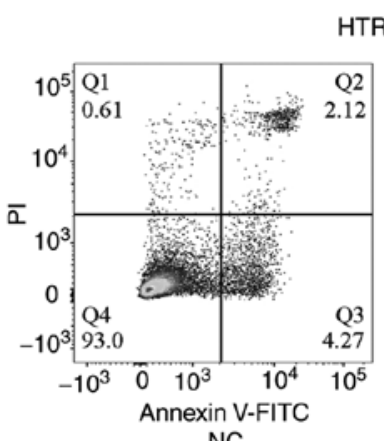

NC

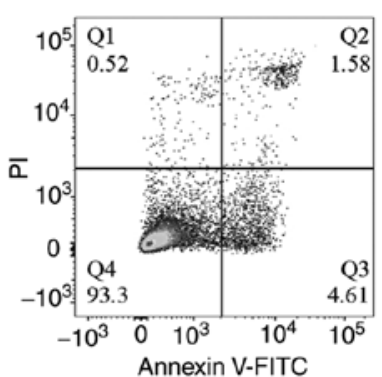

ShEGFR

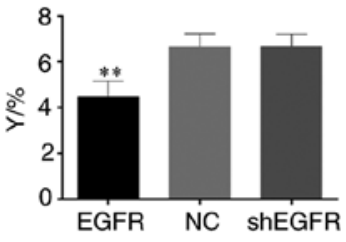

Figure 5. Detection of an association between EGFR expression and apoptosis. ${ }^{*} \mathrm{P}<0.05,{ }^{* *} \mathrm{P}<0.01 \mathrm{vs}$. NC. EGFR in the figure refers to EGFR overexpressing cells, and $\mathrm{Y}$ refers to the percentage of apoptotic cells. NC, negative control; sh, short hairpin.

\section{Discussion}

According to the cell transmission theory, the HBV infection rate gradually decreases from the maternal side of the placenta to the foetal side, whereby the virus infects the placenta in the following order: i) Decidua cell; ii) trophoblast cell; iii) villi interstitial cell; and iv) villi capillary endothelial cell. On the other hand, the OR value of intrauterine infection gradually increases, suggesting that HBV can infect a foetus from the placenta via cell-to-cell transmission $(13,15)$. However, the underlying mechanisms responsible for this remain unclear. Since trophoblast cells form the outermost placental structure, direct contact with maternal blood during pregnancy is the first barrier to HBV passage through the placenta $(32,33)$. Therefore, studying the role of HBV-infected placental trophoblasts is key to clarifying intrauterine HBV infection mechanisms.

High HBV DNA load and HBeAg (+) are risk factors for intrauterine infection (34-36). A previous study found that $\mathrm{HBx} A g$ levels were significantly higher in placental tissues of 
pregnant women with HBV DNA titres $>1 \times 10^{3}$ copies $/ \mathrm{ml}$ than in tissues with HBV DNA titres $<1 \times 10^{3}$ copies/ml (24). In the present study, HBV DNA expression was significantly higher in cells stably transfected with full length wild-type HBV than in cells transfected with $\triangle \mathrm{HBx}$. Expression levels of $\mathrm{HBeAg}$ and pgRNA in cells stably expressing full length wild-type $\mathrm{HBV}$ were significantly higher than those in $\triangle \mathrm{HBX}$-expressing cells. These results indicate that, HBV DNA replication, HBeAg and pgRNA levels are significantly decreased when $\mathrm{HBx}$ is deleted. The present results confirm that $\mathrm{HBx}$ protein promotes HBV replication in placental trophoblast cells, HBx protein expression in trophoblast cells increases with increasing HBV DNA titre in maternal blood and HBx protein expression is regulated by a positive feedback mechanism associated with HBV replication in the host.

The covalently closed circular (ccc)DNA is the template of transcription for 5 viral RNAs necessary for the production of the viral antigens and for viral replication, the latter of which takes place in the cytoplasm after reverse transcription of an overlength pgRNA within newly formed nucleocapsids (37). The transcriptional activity of the cccDNA can be determined by measuring pgRNA contents (38). In the current study, the expression of pgRNA decreased significantly when HBx was absent in the placenta trophoblasts transfected with an HBV plasmid, which indicated that the transcription activity of cccDNA in trophoblasts decreased and the replication of HBV DNA was limited. The current study also demonstrated that $\mathrm{HBx}$ protein can upregulate $\mathrm{HBeAg}$ expression, which further increases the risk of $\mathrm{HBV}$ intrauterine infection.

Smc5/6 is a complex that directly binds DNA and is required for chromosome remodelling and stability $(39,40)$. Smc5/6 has been extensively studied in yeast, but less so in mammals. It has been revealed to serve a role in homologous recombination and in resolving replication-induced DNA supercoiling $(41,42)$. Besides chromosome maintenance, certain data suggest that Smc5/6 binds episomes (including cccDNA) and blocks episome transcription (43). In placental trophoblast cells transfected with $\mathrm{HBx}$ plasmid, Smc5/6 expression was significantly lower compared with in mock-transfected cells. In addition, confocal laser microscopy showed that HBx protein was mainly located in the cytoplasm, whereas Smc5 protein was mainly located in the nucleus. These results are consistent with other published results of studies conducted in hepatoma cells $(21,23)$. It was hypothesized that the HBx protein promotes Smc5/6 degradation in placental trophoblast cells, thereby increasing the transcription of cccDNA, promoting pgRNA synthesis and increasing HBV DNA replication (Fig. S2).

Previous studies found that the expression of PI3K/p-AKT was upregulated and trophoblast apoptosis was significantly inhibited in vitro and in vivo under the condition of high replication (HBV DNA $>1 \times 10^{3}$ copies/ml) $(24,25)$. HBx protein may inhibit trophoblast apoptosis by activating PI3K/p-AKT (44). However, the exact mechanism by which HBx protein activates the PI3K/p-AKT signalling pathway remains unclear, thus indicating the requirement for further study. The HBx gene integrates into the human genome near the EGFR gene and other genes responsible for regulating cell growth, thus affecting intracellular signal transduction (45). EGFR is a membrane surface receptor with tyrosine kinase activity that is widely distributed on the surface of mammalian cells. It can stimulate different signal responses in various cells and activates a variety of downstream signal transduction pathways that are known to stimulate cell proliferation and enhance cell mobility and organ repair, similar to PI3K/p-AKT/Bad and Ras/Raf/MEK/ERK pathways (46). p-EGFR protein is robustly upregulated in $\mathrm{HBx}$-infected human placental tissues and trophoblast cells, $\mathrm{HBx}$ reduces human placental trophoblast cell apoptosis by activating the EGFR/AKT pathway (47). However, the site and mechanism underlying EGFR activation by $\mathrm{HBx}$ remain to be elucidated and require further study.

Co-transfection of $\mathrm{HBx}$ and EGFR promoter plasmids in JEG-3 and HTR- 8 cells significantly elevated EGFR promoter driven luciferase expression relative to the control group. In the present study, it was revealed that $\mathrm{HBx}$ protein acts on the EGFR promoter and activates EGFR promoter driven expression. When EGFR was overexpressed in cells, PI3K and p-AKT were localized to the cytoplasm and PI3K and p-Akt levels significantly increased, whereas AKT expression was not affected. Additionally, the percentage of cells undergoing apoptosis was also significantly decreased. However, when EGFR expression was knocked down in EGFR-overexpressing cells, PI3K and p-AKT levels were significantly decreased, AKT expression was unaffected and the percentage of cells undergoing apoptosis was significantly increased. Collectively, the present results suggest that EGFR promotes AKT phosphorylation in trophoblast cells by increasing expression of its upstream effector, PI3K, which inhibits apoptosis. The present study demonstrated that HBx protein activates EGFR expression by acting on the EGFR promoter in placental trophoblast cells and inhibits trophoblast cell apoptosis via the downstream $\mathrm{PI} 3 \mathrm{~K} / \mathrm{p}-\mathrm{AKT}$ signalling pathway (Fig. S2).

In conclusion, $\mathrm{HBx}$ protein expression increased in trophoblast cells with increasing titres of HBV DNA in maternal blood. The findings of the present study indicate that $\mathrm{HBx}$ protein promotes Smc5/6 degradation to enhance HBV replication in placental trophoblast cells. Furthermore, HBx protein expression is upregulated by increasing HBV replication. HBx protein also activates EGFR expression by acting on the EGFR promoter and inhibits trophoblast cell apoptosis via the downstream PI3K/p-AKT signalling pathway. HBx prolongs the life of trophoblast cells infected with HBV and provides a latent place for viruses to escape (48). It was hypothesised that the HBx protein, via its functions described above, is involved in the mechanism underlying viral infection of placental trophoblast cells and foetuses, thereby promoting the development of HBV intrauterine infection. Therefore, $\mathrm{HBx}$ protein plays a crucial role in HBV infection of placental trophoblasts and increases intrauterine infection risk.

\section{Acknowledgements}

The authors would like to acknowledge the technical assistance provided by Mrs. Rongjuan Chen (Institute of Infectious Diseases, 5th Medical Center of Chinese PLA General Hospital, Beijing); Mrs. Lanlan Si (Institute of Infectious Diseases, 5th Medical Center of Chinese PLA General Hospital, Beijing); Dr Kai Zhang (Institute of Infectious Diseases, Xiang'an Hospital of Xiamen University); and Mr. Qi Li (Institute of 
Infectious Diseases, 5th Medical Center of Chinese PLA General Hospital, Beijing).

\section{Funding}

The present study was supported by the National Natural Science Foundation of China (grant no. 81370721) and the National Natural Science Foundation of China (grant no. 81771615).

\section{Availability of data and materials}

The datasets used and/or analyzed during the current study are available from the corresponding author on reasonable request.

\section{Authors' contributions}

GB conceived and designed the experiments. YL and DX provided the resources and designed the experiments. YYL, WZ and FG performed the experiments. YYL and YZ analyzed the data. YYL and GB wrote the paper. YYL and GB confirmed the authenticity of all the raw data. All authors read and approved the final manuscript.

\section{Ethics approval and consent to participate}

The study protocol was approved by the Institutional Review Board of the First Affiliated Hospital, Xi'an Jiaotong University. All experiments were performed in accordance with applicable guidelines and regulations. Informed written consent was obtained from all study participants after a detailed explanation of the study at the time of blood and serum collection.

\section{Patient consent for publication}

Not applicable.

\section{Competing interests}

The authors declare that they have no competing interests.

\section{References}

1. Dandri M: Epigenetic modulation in chronic hepatitis B virus infection. Semin Immunopathol 42: 173-185, 2020.

2. Liu CJ and Kao JH: NOhep: Toward Global Control of Hepatitis B virus infection-an introduction. J Infect Dis 216 (Suppl 8): S749, 2017.

3. Maini MK and Bertoletti A: HBV in 2016: Global and immunotherapeutic insights into hepatitis B. Nat Rev Gastroentero Hepatol 14: 71-72, 2017.

4. Wu Q, Xu C, Li J, Li L, Yan G, Yue L, Zeng Y, Huang H, Deng G and Wang Y: Evolution and mutations of hepatitis B virus quasispecies in genotype $\mathrm{B}$ and $\mathrm{C}$ during vertical transmission. J Med Virol 88: 1018-1026, 2016.

5. Eke AC, Eleje GU, Eke UA, Xia Y and Liu J: Hepatitis B immunoglobulin during pregnancy for prevention of mother-to-child transmission of hepatitis B virus. The Cochrane Database Syst Rev 2: CD008545, 2017.

6. Li Y, Shen C, Yang L, Yang Y, Wang M, Li S, Chen F, Yang M, Peng L, Ma J, et al: Intra-host diversity of hepatitis B virus during mother-to-child transmission: The $\mathrm{X}$ gene may play a key role in virus survival in children after transmission. Arch Virol 165: 1279-1288, 2020.
7. Gong $\mathrm{J}$ and Liu X: Effect of HBIG combined with hepatitis B vaccine on blocking HBV transmission between mother and infant and its effect on immune cells. Exp Ther Med 15: 919-923, 2018.

8. Su WJ, Chen HL and Chang MH: Breakthrough hepatitis B Virus (HBV) infection from mother-to-infant transmission is the key problem hindering HBV eradication. J Infect Dis 208: 1036-1037, 2013.

9. Liu J, Feng Y, Wang J, Li X, Lei C, Jin D, Feng W, Yang Y, He Y, Li Y, et al: An 'immune barrier' is formed in the placenta by hepatitis B immunoglobulin to protect the fetus from hepatitis B virus infection from the mother. Hum Vaccin Immunother 11: 2068-2076, 2015.

10. Wang DD, Yi LZ, Wu LN, Yang ZQ, Hao HY, Shi XH, Wang B, Feng SY, Feng YL and Wang SP: Relationship between maternal PBMC HBV cccDNA and HBV serological markers and its effect on HBV intrauterine transmission. Biomed Environ Sci 32: 315-323, 2019.

11. Bai GQ, Li SH, Yue YF and Shi L: The study on role of peripheral blood mononuclear cell in HBV intrauterine infection. Arch Gynecol Obstet 283: 317-321, 2011.

12. Ke C, Xiao X, Gan L and Zhou Y: Preliminary study of hepatitis $\mathrm{B}$ virus replication in primary placental trophoblastic cells. Prog Obstet Gynecol 24: 1-5, 2015

13. Chen Y, Wang L, Xu Y, Liu X, Li S, Qian Q, Hu B, Zhou A, Chen $T$ and Zhao Y: Role of maternal viremia and placental infection in hepatitis B virus intrauterine transmission. Microbes Infect 15: 409-415, 2013.

14. Zhao Y, Di F and Zhong Y: Progress in research on mechanism of HBV intrauterine transmission. Chin $\mathrm{J}$ Clin (Electronic Edition) 9: 1433-1436, 2015

15. Zhang SL, Yue YF, Bai GQ, Shi L and Jiang H: Mechanism of intrauterine infection of hepatitis $B$ virus. World J Gastroenterol 10: 437-438, 2004.

16. Zuo Y, Li D, Xu D, Chen C and Wang X: Meta-analysis of intrauterine infection rate of $\mathrm{HBV}$ in different periods of pregnancy. J Fourth Military Med Univ 9: 853-855, 2002 (In Chinese).

17. Feitelson MA, Bonamassa B and Arzumanyan A: The roles of hepatitis $B$ virus-encoded $X$ protein in virus replication and the pathogenesis of chronic liver disease. Expert Opin Ther Targets 18: 293-306, 2014

18. Lee HR, Cho YY,Lee GY, You DG, Yoo YD and Kim YJ: A direct role for hepatitis $\mathrm{B}$ virus $\mathrm{X}$ protein in inducing mitochondrial membrane permeabilization. J Viral Hepat 25: 412-420, 2018.

19. Zoulim F, Saputelli J and Seeger C: Woodchuck hepatitis virus $\mathrm{X}$ protein is required for viral infection in vivo. J Virol 68: 2026-2030, 1994.

20. Lucifora J, Arzberger S, Durantel D, Belloni L, Strubin M, Levrero M, Zoulim F, Hantz O and Protzer U: Hepatitis B virus $\mathrm{X}$ protein is essential to initiate and maintain virus replication after infection. J Hepatol 55: 996-1003, 2011.

21. Decorsiere A, Mueller H, van Breugel PC, Abdul F, Gerossier L, Beran RK, Livingston CM, Niu C, Fletcher SP, Hantz O and Strubin M: Hepatitis B virus X protein identifies the Smc5/6 complex as a host restriction factor. Nature 531: 386-389, 2016.

22. Mitra B and Guo H: Hepatitis B virus $X$ protein crosses out Smc5/6 complex to maintain covalently closed circular DNA transcription. Hepatology 64: 2246-2249, 2016.

23. Murphy CM, Xu Y, Li F, Nio K, Reszka-Blanco N, Li X, Wu Y, Yu Y, Xiong Y and Su L: Hepatitis B virus X protein promotes degradation of SMC5/6 to enhance HBV replication. Cell Rep 16: 2846-2854, 2016

24. Bai G, Wang Y, Zhang L, Tang Y and Fu F: The study on the role of hepatitis B virus X protein and apoptosis in HBV intrauterine infection. Arch Gynecol Obstet 285: 943-949, 2012.

25. Bai G, Fu F, Tang Y and Wang Y: Effect of hepatitis B virus infection on apoptosis of a human choriocarcinoma cell line in vitro. J Obstet Gynaecol Res 39: 1200-1211, 2013.

26. Hung CM, Huang WC, Pan HL, Chien PH, Lin CW, Chen LC, Chien YF, Lin CC, Leow KH, Chen WS, et al: Hepatitis B Virus X upregulates HuR protein level to stabilize HER2 expression in hepatocellular carcinoma cells. Biomed Res Int 2014: 827415, 2014.

27. Chen JY, Chen YJ, Yen CJ, Chen WS and Huang WC: HBx sensitizes hepatocellular carcinoma cells to lapatinib by up-regulating ErbB3. Oncotarget 7: 473-489, 2016.

28. Graham CH, Hawley TS, Hawley RG, MacDougall JR, Kerbel RS, Khoo N and Lala PK: Establishment and characterization of first trimester human trophoblast cells with extended lifespan. Exp Cell Res 206: 204-211, 1993. 
29. Abou-Kheir W,Barrak J,Hadadeh O and Daoud G: HTR-8/SVneo cell line contains a mixed population of cells. Placenta 50: 1-7, 2017.

30. Wang J, Shen T, Huang X, Kumar GR, Chen X, Zeng Z, Zhang R, Chen $\mathrm{R}$, Li T, Zhang T, et al: Serum hepatitis B virus RNA is encapsidated pregenome RNA that may be associated with persistence of viral infection and rebound. J Hepatol 65: 700-710, 2016.

31. Huang H, Wang J, Li W, Chen R, Chen X, Zhang F, Xu D and Lu F: Serum HBV DNA plus RNA shows superiority in reflecting the activity of intrahepatic cccDNA in treatment-naïve HBV-infected individuals. J Clin Virol 99-100: 71-78, 2018.

32. Ma L, Alla NR, Li X, Mynbaev OA and Shi Z: Mother-to-child transmission of HBV: Review of current clinical management and prevention strategies. Rev Med Virol 24: 396-406, 2014.

33. Mavilia MG and Wu GY: Mechanisms and prevention of vertical transmission in chronic viral hepatitis. J Clin Transl Hepatol 5: 119-129, 2017.

34. Peng S, Wan Z, Liu T, Zhu H and Du Y: Incidence and risk factors of intrauterine transmission among pregnant women with chronic hepatitis B virus infection. J Clin Gastroenterol 53: $51-57,2019$.

35. Xiao Y, Sun K, Duan Z, Liu Z, Li Y, Yan L, Song Y, Zou H, Zhuang $\mathrm{H}$, Wang $\mathrm{J}$ and Li J: Quasispecies characteristic in ' $a$ ' determinant region is a potential predictor for the risk of immunoprophylaxis failure of mother-to-child-transmission of sub-genotype $\mathrm{C} 2$ hepatitis $\mathrm{B}$ virus: A prospective nested case-control study. Gut 69: 933-941, 2020.

36. Shih YF and Liu CJ: Mother-to-infant transmission of hepatitis B virus: Challenges and perspectives. Hepatol Int 11: 481-484, 2017.

37. Allweiss L and Dandri M: The role of cccDNA in HBV maintenance. Viruses 9: 156, 2017.

38. Giersch K, Allweiss L, Volz T, Dandri M and Lutgehetmann M: Serum HBV pgRNA as a clinical marker for cccDNA activity. J Hepatol 66: 460-462, 2017.

39. Abdul F, Filleton F, Gerossier L, Paturel A, Hall J, Strubin M and Etienne L: Smc5/6 antagonism by $\mathrm{HBx}$ is an evolutionarily conserved function of Hepatitis B virus infection in mammals. J Virol 92: e00769-18, 2018.
40. Liang TJ: Virology: The X-Files of hepatitis B. Nature 531: 313-314, 2016.

41. Jeppsson K, Carlborg KK, Nakato R, Berta DG, Lilienthal I, Kanno T, Lindqvist A, Brink MC, Dantuma NP, Katou Y, et al: The chromosomal association of the Smc5/6 complex depends on cohesion and predicts the level of sister chromatid entanglement. PLoS Genet 10: e1004680, 2014.

42. Jeppsson K, Kanno T, Shirahige K and Sjogren C: The maintenance of chromosome structure: Positioning and functioning of SMC complexes. Nature reviews. Molecular cell biology 15: 601-614, 2014

43. Van Breugel PC, Robert EI, Mueller H, Decorsière A, Zoulim F, Hantz O and Strubin M: Hepatitis B virus X protein stimulates gene expression selectively from extrachromosomal DNA templates. Hepatology 56: 2116-2124, 2012.

44. Wang W, Shi Y, Bai G, Tang Y, Yuan Y, Zhang T and Li C: HBxAg suppresses apoptosis of human placental trophoblastic cell lines via activation of the PI3K/Akt pathway. Cell Biol Int 40: 708-715, 2016.

45. Chen YJ, Chien PH, Chen WS, Chien YF, Hsu YY, Wang LY, Chen JY, Lin CW, Huang TC, Yu YL and Huang WC: Hepatitis $B$ virus-encoded $X$ protein downregulates EGFR expression via inducing MicroRNA-7 in hepatocellular carcinoma cells. Evid Based Complement Alternat Med 2013: 682380, 2013.

46. Wee P and Wang Z: Epidermal growth factor receptor cell proliferation signaling pathways. Cancers (Basel) 9: 52, 2017.

47. Wang W, Bai G, Zhang Y, Zhang T, Li C, Yuan Y, Liu S and Wang C: HBxAg suppresses cell apoptosis and promotes the secretion of placental hormones in human placental trophoblasts via activation of the EGFR/Akt pathway. Cell Biol Int 42: 237-247, 2018

48. Rawat $\mathrm{S}$ and Bouchard MJ: The hepatitis B virus (HBV) $\mathrm{HBx}$ protein activates AKT to simultaneously regulate $\mathrm{HBV}$ replication and hepatocyte survival. J Virol 89: 999-1012, 2015.

This work is licensed under a Creative Commons Attribution-NonCommercial-NoDerivatives 4.0 International (CC BY-NC-ND 4.0) License. 